the relative probability of past behaviours when modern behaviours are so variable? Having pointedly raised these issues, the book disappoints because it does not offer any principles for doing a better job of reading the past.

The book is also flawed by appallingly poor attention to fact-checking. The authors misplace Olduvai Gorge and Laetoli in Kenya (they are in Tanzania); they call Mary and Louis Leakey palaeontologists instead of archaeologists; they cite Homo as the first of "what could at the time be called the hominid [hominin] line" (a grossly inaccurate remark because australopithecines are also hominins or hominids); and they mistakenly state that the carbon isotopes that distinguish grasseaters from tree-eaters are ${ }^{14} \mathrm{C}$ and ${ }^{13} \mathrm{C}$, rather than ${ }^{13} \mathrm{C}$ and ${ }^{12} \mathrm{C}$.

Unforgiveably, there are no notes in the book to identify the sources of either direct quotations or specific points of information. These glaring defects undercut the credibility of this otherwise intelligent and provocative work. Pat Shipman is adjunct professor of anthropology, Pennsylvania State University, 315 Carpenter Building, University Park, Pennsylvania 16802, USA.

\title{
When the numbers don't add up
}

\section{Useless Arithmetic: Why Environmental Scientists Can't Predict the Future by Orrin Pilkey \& Linda Pilkey-Jarvis Columbia University Press: 2007. 230 pp. $\$ 29.50, \pm 19$}

\section{Roger Pielke Jr}

The central thesis of Useless Arithmetic, by the father-and-daughter team of Orrin Pilkey and Linda Pilkey-Jarvis, is "the virtual impossibility of accurate quantitative modelling to predict the outcome of natural processes on the Earth's surface". This is sure to cause cognitive dissonance among many readers - it simply does not seem to accord with our lived experience.

As I write this review, I'm sitting on an aircraft safely crossing the United States. The plane was created with quantitative aeronautical engineering design models, its flight path dictated by quantitative routing models, and the snowy weather I experienced at takeoff was predicted by quantitative weatherforecasting models. Such experiences in successfully predicting and managing natural processes would seem to indicate that without mathematical models our twenty-first-century lives would simply be impossible. What could have influenced the authors to make claims so strongly contradicted by experience?

The authors answer this question unambiguously and definitively by discussing some two dozen instances (seven of which are examined in detail) in which decision-making, and in some cases science, based on mathematical modelling has gone awry, leading to undesired societal and environmental outcomes.

The difference between my flight and failed predictions and mismanagement of fisheries, say, is an important part of the book's argument. In engineering design, flight-path routing and weather prediction, quantitative models are produced and used in a different way from those used by policy-makers for fisheries management, sea-level rise, beach nourishment and the disposal of nuclear waste. However, many of the nuances and complexities involved in understanding these differences are hard to discern in the high-level, non-technical overview provided in Useless Arithmetic. For example, the book hints at the contextual importance of open and closed systems, consolidative and exploratory modelling, and epistemic (knowable) versus aleatory (random) uncertainties, but it does not provide the in-depth treatment needed to really understand these differences or their significance. Readers seeking to have their dissonance resolved may wish that the authors had explained these issues, rather than merely hinted at them. But those wanting more depth will find some useful pointers to accessible literature in a concise but useful bibliography.

The authors point out that modelling results "are easier to live with if they follow preconceived or politically correct notions", and the chapter on sealevel rise related to human-caused global warming seems to bear this out. In most chapters, the authors focus on a critique of models, modellers and model users. On climate change they choose instead to sandwich their critique of sea-level-rise models with an even stronger critique of Republican senator James Inhofe and author Michael Crichton, both of whom have strongly taken issue with the science of climate modelling and action on climate change. Yet the following authors' comments would have been equally at home in one of Inhofe's speeches or in Crichton's sceptical novel State of Fear (HarperCollins, 2004): "the juggernaut, the large industry that has risen to answer questions about global climate change, global warming, sea level rise, and all their ramifications, has unstoppable momentum... leaders in global change studies tend to view as a primary task the maintenance of funding for the modelling juggernaut." Have the authors lost their nerve when discussing the politically sensitive issue of climate change? Even so, their strong views on modelling in climate science are difficult to miss.

Despite these quibbles, this is a valuable book for the very reason that it causes dissonance. Using well-documented cases of policy failure, the authors have identified a critical challenge confronting the modern scientific enterprise: our ability to produce model-based predictions seems to have outpaced our ability to use such tools wisely in decision-making. The results are seen in bad policies and bad science.

So what to do? The authors' plea for a world without models is unrealistic, and not simply because scientists will continue to produce them. A story related by the Nobel prizewinning economist Kenneth Arrow explains why. As a weather forecaster in the Second World War, Arrow and his colleagues were

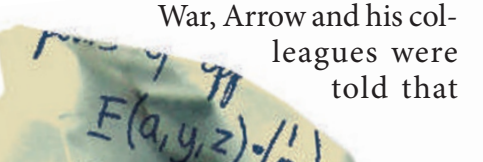


decision-makers and produced by scientists.

If quantitative models are here to stay, an important question to ask is how we can improve the way we create and apply models in science and policy. The authors provide some useful guidance by suggesting that we need to be more qualitative in how we model, for instance by recognizing that all current data and analysis point to sea levels rising for the foreseeable future, with some extreme scenarios that cannot be ruled out or even quantified probabilistically, but with a more honest admission that accurate prediction of longterm rates and totals is beyond our abilities.
Qualitative modelling supports adaptive decision-making under uncertainty, where commitments are tentative and continuously re-evaluated in the light of experience. Adaptive management does not exclude long-term planning, but it could help us to avoid the big mistakes made when we act as if we know more than we actually do. And as Useless Arithmetic details, making big mistakes based on the misuse of quantitative models is far more common than it should be.

Roger Pielke Jr is at the Center for Science and Technology Policy Research, University of Colorado/CIRES, Boulder, Colorado 80309, USA.

\section{Science set in stone}

\section{Swimming in Stone: The Amazing Gogo Fossils of the Kimberley \\ by John Long \\ Fremantle Arts Centre Press: 2007. 320 pp. $\$ 26.95$}

\section{Per E. Ahlberg}

Palaeontology is essentially a science of serendipity. Most of biology rests on the planning and execution of experiments that may or may not work; palaeontologists plan and carry out expeditions to look for fossils that may or may not be there. Of course, this base of collected specimens supports an analytical superstructure as organized and strategically constructed as any other. But behind the meticulous published analyses there lurks the faintly thrilling - or unsettling - realization that a loose rock left unturned, or a lunch break taken in a different spot on the hillside, could have caused a specimen or even a whole locality of critical scientific importance to remain undiscovered.

In Swimming in Stone, John Long tells the story of one of these critically important localities: Gogo in Western Australia. Here, at Go Go Station near Fitzroy Crossing in the tropical north of the state, yellow limestone nodules weathering out on a plain backed by oddly abrupt hills yield 380-million-year-old fossil fishes of such extraordinary perfection that, in some specimens, the jaws can be smoothly opened and closed without grating on their hinges. The whole landscape is, in fact, a gigantic fossil: the hills were once a barrier reef with outlying atolls, and the black soil of the plain is the mud that accumulated on the fore-reef slope. Limestone nodules formed around animal carcasses in this mud, preserving them perfectly to the present day. The locality was discovered in 1940 when the first fossil fish was collected by geologist

Curt Teichert, a refugee from Nazi Germany. Long, currently head of science at Museum Victoria . in Melbourne, has been collecting fossils there for more than 20 years.
After opening with a brief scene-setting introduction, including an imagined dive on the Gogo reef, the first main section of the book charts the history of the site from its discovery, through collecting trips by British and Australian teams, to the period since the 1980 s when Long became the driving force behind the collecting programme. Intertwined with this narrative of hard slog and lucky chance are vivid thumbnail portraits of the major players, such as Teichert, Harry Toombs and George Kendrick. There are also accounts of technical advances (crucially the development of fossil preparation using acetic acid, which revealed the full glory of the Gogo fishes) and scientific controversies over the Gogo material. These included not only issues of anatomical interpretation, but also a rather tense dispute between the Western Australian Museum in Perth and the then
British Museum of Natural History in London over the ultimate repository of type specimens, which, thankfully, was resolved amicably.

Long's writing style is breezy and engaging, showing the skill of an experienced writer. If you ever wanted to know what can befall you on a fossil-collecting expedition, it's all here - everything from broken-down vehicles, to dingoes trailing you in hopeful expectation of your death, to sharing the remote and isolated collecting area with an armed serial killer on the run. Helpful marginal notes explain scientific concepts such as phylogeny (the science of family trees) and fieldwork trivia such as death adders (beautifully camouflaged and extremely venomous snakes).

The second section of the book continues in the same accessible vein with an overview of the scientific importance of the Gogo fossils and their place in the emerging story of early vertebrate evolution. This is not a comprehensive account - for that I would recommend Philippe Janvier's Early Vertebrates (Oxford University Press, 1996) - and different researchers in the field will no doubt have their own disagreements with parts of it, but for those new to the subject it is an excellent introduction. It also demonstrates how progress in vertebrate palaeontology depends on the discovery of top-quality specimens, fossils so well preserved that anatomical and functional questions can be answered without ambiguity.

Of course, there are quibbles: giant dragonflies are not known from the Devonian, and Erik Jarvik and Erik Stensiö were not directors of the Swedish Museum of Natural History, although they did head the palaeozoology section.

There is also one serious omission:

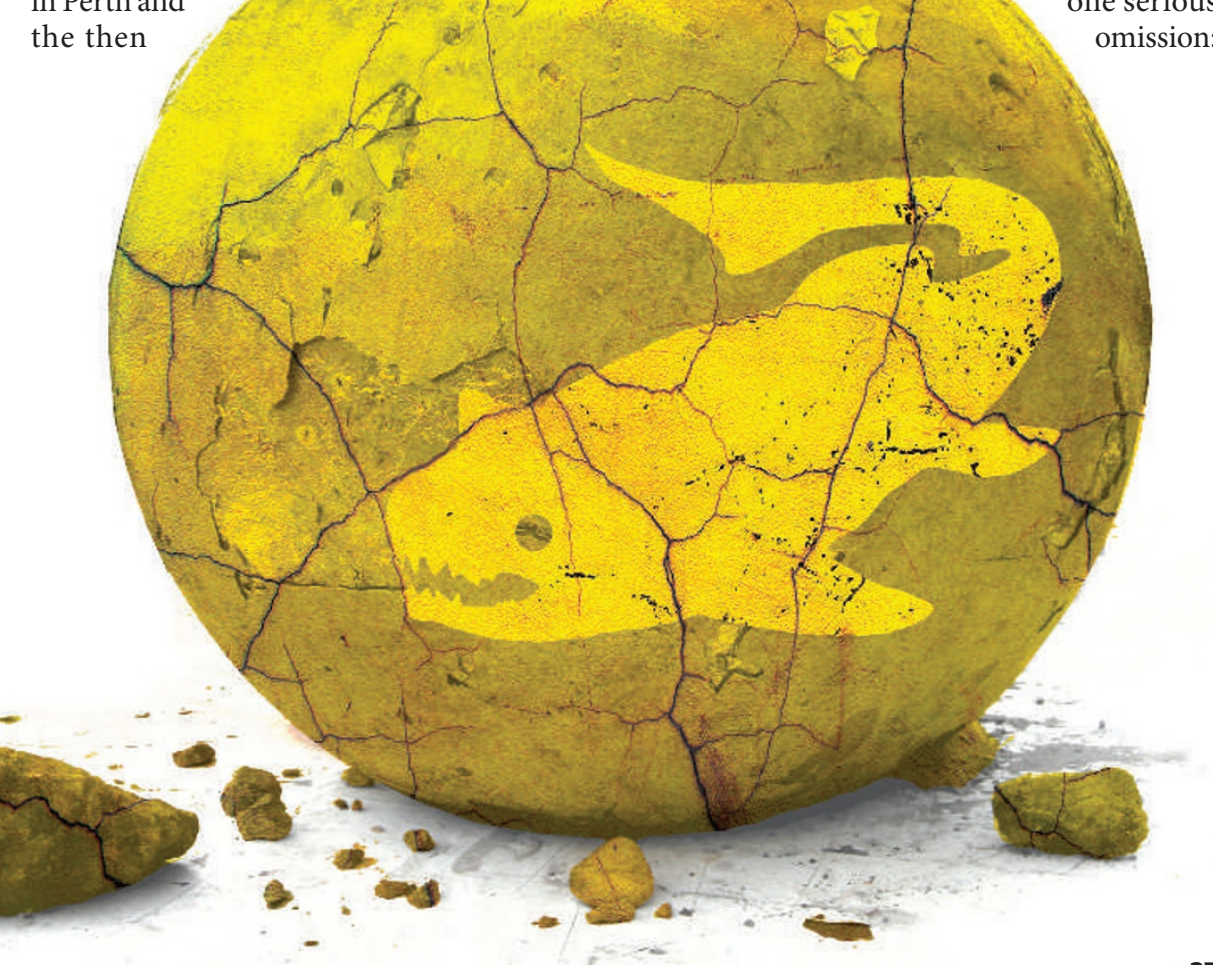

